\title{
Fuzzy systems and applications in innovation and sustainability
}

\author{
Ernesto Leon-Castro \\ Fabio Blanco-Mesa \\ Victor Alfaro-Garcia \\ Anna M. Gil-Lafuente \\ and Jose M. Merigo
}

\section{Evolution of fuzzy systems}

One of the main characteristics of humankind is the ability to interpret via natural language incomplete, imprecise, vague, subjective, fragmentary, or scarce information i.e. information in uncertainty and transform it to actions, reason and decision-making [9]. Fuzzy sets theory firstly introduced the treatment of such concepts in 1965 with the foremost influential paper "Fuzzy Sets" [29]. The groundbreaking standpoint of fuzzy systems allows the treatment of uncertain information with the utilization of a strict mathematical framework [8]. Ever since the publication of the pivotal paper from Zadeh, a plethora of contributions have shaped the fuzzy sets theory scope and applications, from developments in engineering, mathematics, computer, decision, life, physical, health, social sciences and humanities [17].

Fuzzy sets theory-oriented solutions have proven to be effective when addressing human-like dynamic systems [20], however, the path to a formal representation of vagueness has been a demanding endeavor. This is particularly observed in the $1950 \mathrm{~s}$ as several attempts were made, especially trying to capture and augment logic capabilities' representation, however not fully addressing the main concept [12]. A breakthrough is observed with the introduction of Zadeh's membership function and truth values [30], a notion of gradualness of the proposed Possibility Theory [34]. Nonetheless, classical standpoints compelled critical arguments to these ideas [35]. The skepticism towards the newly introduced fuzzy logic theory strongly decayed with the rapid advancements of information technologies, the capabilities of translating human-like thinking using fuzzy sets, fuzzy relations [31], fuzzy systems [32], fuzzy intervals and approximate reasoning [33], fruitful developments in several fields of knowledge [2].

The wide-ranging properties of fuzzy logic theory motivated numerous extensions and generalizations e.g. type-2 fuzzy sets $[21,33]$, intuitionistic fuzzy sets [5], interval-valued intuitionistic fuzzy sets [6, 7], fuzzy multi sets [27], hesitant fuzzy sets [23], Pythagorean fuzzy sets [28], among others. These 
advancements comprehend an evolving toolbox of robust methodological approaches that allows academics, decision, and policy makers to address problems that require the inclusion and modelling of quantitative and qualitative data, a particularity that results especially interesting in social sciences $[4,10$, 15, 37]. Moreover, these advancements are of interest in management and business challenges and situations, where flexible and agile solutions are required to be determined without leaving the required formal mathematical methods behind $[14,18]$.

\section{Applications in innovation and sustainability}

Based on the above, the advances in the application and use of diffuse methodologies for the treatment and analysis of information in the different areas of business management. One of the areas in which the application of these methodologies has ventured is related to innovation. These methodologies have been used to explain aspects related to innovation. Within these developments, the following approaches stand out: 1) Product development, which seeks to establish relationships between product development project characteristics and project outcomes [22], 2) Innovation capability and capacity, which are focused on measuring TICs requires Technology innovation and evaluation for the innovation capacity of financial institutions [16, 24], 3) Innovation collaboration highlights the importance Collaboration for innovation and innovative to gain competitive advantage tools [19], 4) Green Technology shows to analyze the combination and convergence of energy-intensive industries developed by ecological factors based on energy clusters [26], 5) Service innovation is focused on identifying and analyzing the factors that influence it [13], 6) Innovation Performance evaluates different financial and nonfinancial criteria in banking industry [25], 7) Innovation diffusion analyses the transfer of innovation and knowledge in mega-projects through project management [36], 8) Innovation support systems proposes a support system to evaluate innovation performance in higher education institutes [11] and 9) Innovation management measurement proposes a fuzzy tools for innovation activities measurement in small and medium manufacturing enterprises [3]. Thus, it can be seen how these approaches seek to explain or measure innovation activities using diffuse techniques in different sectors.
Of the approaches presented, the one related to the measurement of innovation management can be highlighted, since it contemplates in a holistic way how innovation is directed in small and medium enterprises. This proposition is focused on seven key innovation measurement dimensions consider innovation strategy, knowledge management, project management, new product portfolio management, the organization and structure of the firm, and external drivers $[1,3]$. Also, expertons and aggregation operators allow to integrate subjective and objective dataset of these dimension in order to give a better information analysis and comprehend how firms carry out innovation activities [38]. Thus, this approach allows an accurate interpretation based on the specific conditions of the problem based on the flexibility of the parameters [3].

In this sense, the methods and applications of the tools coming from the field of fuzzy and uncertainty studies offer new perspectives for the treatment of the problems of business management and economy. In this specific case, related to innovation management, there are several proposals that have been developed with different approaches and that make the field attractive to continue proposing and developing research.

\section{About the papers in this special issue}

The special issue consists of 23 papers that have been presented in the III International Congress in Innovation and Sustainability that was held in Concepcion, Chile from 24-25 October 2019. The best papers were invited to be presented in this Special Issue. All the papers have been processed by a peer review process.

The papers in the special issue present different formulations and applications of fuzzy systems to approach a better understanding and solving different problems in different areas of innovation and sustainability. Among the main topics that can be found in the Special Issue are economic performance, information and communication technologies, women entrepreneurship, investment portfolios, innovation management, business size, customer relationship, tourism and destination competitiveness, supplier selection, balance score card, new business ventures, government transparency, sustainable tourism, price prediction, consumer behavior, bank efficiency and personality trait. 


\section{Acknowledgments}

We would like to thank the Red Iberoamericana de Competitividad, Innovacion y Desarrollo (REDCID), specially the members of the project number 616RT0515 for their help that has been essential for the realization of the congress. We also like to acknowledge all the reviewers for their support in the evaluation of the papers submitted to this special issue. Finally, Author Leon-Castro acknowledges support from Chilean Government trough FONDECYT initiation grant No. 11190056.

\section{References}

[1] R. Adams, J. Bessant and R. Phelps, Innovation management measurement: A review, International Journal of Management Reviews 8(1) (2006), 21-47.

[2] V.G. Alfaro-García, Toma de decisiones en la incertidumbre: técnicas y herramientas ante escenarios altamente desafiantes, Inquietud Empresarial 19(2) (2020), I-III.

[3] V.G. Alfaro-Garcia, A.M. Gil-Lafuente and G.G. Alfaro Calderon, A fuzzy methodology for innovation management measurement, Kybernetes 46(1) (2017), 50-66.

[4] V.G. Alfaro-García, J.M. Merigó, G.G. Alfaro-Calderón, L. Plata-Pérez, A.M. Gil-Lafuente and E. Herrera-Viedma, A citation analysis of fuzzy research by universities and countries, Journal of Intelligent \& Fuzzy Systems 38(5) (2020), 5355-5367.

[5] K. Atanassov, Intuitionistic fuzzy sets, Fuzzy Sets and Systems 20(1) (1986), 87-96.

[6] K.T. Atanassov, Interval-valued intuitionistic fuzzy sets, In Studies in Fuzziness and Soft Computing (1st ed.). Cham: Springer International Publishing, (2020).

[7] K. Atanassov and G. Gargov, Interval valued intuitionistic fuzzy sets, Fuzzy Sets and Systems 31(3) (1989), 343-349.

[8] B. Bede, Mathematics of fuzzy sets and fuzzy logic. Berlin, Heidelberg: Springer Berlin Heidelberg, (2013).

[9] F. Blanco-Mesa, J.M. Merigó and A.M. Gil-Lafuente, Fuzzy decision making: a bibliometric-based review, Journal of Intelligent \& Fuzzy Systems 32(3) (2017), 2033-2050.

[10] F. Blanco-Mesa, La ciencia de la decisión, Revista UIS Ingenierías 19(2) (2020), I-V.

[11] J.-K. Chen and I.-S. Chen, Using a novel conjunctive MCDM approach based on DEMATEL, fuzzy ANP, and TOPSIS as an innovation support system for Taiwanese higher education, Expert Systems with Applications 37(3) (2010), 1981-1990.

[12] D. Dubois and H. Prade, The emergence of fuzzy sets: a historical perspective. In Studies in Fuzziness and Soft Computing (pp. 3-19). Springer-Verlag Berlin Heidelberg, (2016).

[13] C. Feng and R. Ma, Identification of the factors that influence service innovation in manufacturing enterprises by using the fuzzy DEMATEL method, Journal of Cleaner Production 253 (2020), 120002.

[14] J. Gil-Aluja, Elements for a Theory of Decision in Uncertainty. Dordrecht: Kluwer Academic Publishers, (1999).

[15] A.M. Gil-Lafuente, Fuzzy logic in financial analysis (1st ed.). Berlin/Heidelberg: Springer-Verlag, (2005).
[16] Q. Jun, H. Dinçer and S. Yüksel, Stochastic hybrid decisionmaking based on interval type 2 fuzzy sets for measuring the innovation capacities of financial institutions, International Journal of Finance \& Economics, ijfe.1805, (2020).

[17] C. Kahraman, B. Öztayşi and S. Çevik Onar, A comprehensive literature review of 50 years of fuzzy set theory, International Journal of Computational Intelligence Systems 9(sup1) (2016), 3-24.

[18] A. Kaufmann and J. Gil-Aluja, Introducción de la teoría de los subconjuntos borrosos a la gestión de las empresas. Santiago de Compostela: Milladoiro, (1986).

[19] B. Kaya, A.M. Abubakar, E. Behravesh, H. Yildiz and I.S. Mert, Antecedents of innovative performance: Findings from PLS-SEM and fuzzy sets (fsQCA), Journal of Business Research 114 (2020), 278-289.

[20] G. Klir and B. Yuan, Fuzzy sets and fuzzy logic: theory and applications. In Journal of Chemical Information and Computer Sciences. Upper Saddle River, NJ: Prentice Hall, (1995).

[21] J. Mendel, Type-2 fuzzy sets and systems: an overview [corrected reprint], IEEE Computational Intelligence Magazine 2(2) (2007), 20-29.

[22] M.V. Tatikonda and S.R. Rosenthal, Technology novelty, project complexity, and product development project execution success: a deeper look at task uncertainty in product innovation, IEEE Transactions on Engineering Management 47(1) (2000), 74-87.

[23] V. Torra, Hesitant fuzzy sets, International Journal of Intelligent Systems 25(6) (2010), 529-539.

[24] C. Wang, I. Lu and C. Chen, Evaluating firm technological innovation capability under uncertainty, Technovation 28(6) (2008), 349-363. https://doi.org/10.1016/ J.TECHNOVATION.2007.10.007

[25] S. Wang, Q. Liu, H. Dinçer and S. Yüksel, Analysis of Innovation Performance for Retail Banking Industry With the Hybrid Fuzzy Decision-Making Approach, SAGE Open 10(2) (2020), 215824402092742.

[26] X. Xu, Y. Sun, S. Krishnamoorthy and K. Chandran, An Empirical Analysis of Green Technology Innovation and Ecological Efficiency Based on a Greenhouse Evolutionary Ventilation Algorithm Fuzzy-Model, Sustainability 12(9) (2020), 3886.

[27] R.R. Yager, On the theory of bags, International Journal of General Systems 13(1) (1986), 23-37.

[28] R.R. Yager, Pythagorean fuzzy subsets. 2013 Joint IFSA World Congress and NAFIPS Annual Meeting (IFSA/NAFIPS), 57-61. Edmonton, AB, Canada, (2013).

[29] L.A. Zadeh, Fuzzy sets, Information and Control 8(3) (1965), 338-353.

[30] L.A. Zadeh, Fuzzy algorithms, Information and Control 12(2) (1968), 94-102.

[31] L.A. Zadeh, Similarity relations and fuzzy orderings, Information Sciences 3(2) (1971), 177-200.

[32] L.A. Zadeh, Outline of a new approach to the analysis of complex systems and decision processes, IEEE Transactions on Systems, Man, and Cybernetics, SMC- 3(1) (1973), 28-44.

[33] L.A. Zadeh, The concept of a linguistic variable and its application to approximate reasoning-I, Information Sciences 8 (1975), 199-249.

[34] L.A. Zadeh, Fuzzy sets as a basis for a theory of possibility, Fuzzy Sets and Systems 1(1) (1978), 3-28.

[35] L.A. Zadeh, Is there a need for fuzzy logic? Information Sciences 178(13) (2008), 2751-2779. 
[36] Y. Zhang, H.-H. Wei, D. Zhao, Y. Han and J. Chen, Understanding innovation diffusion and adoption strategies in megaproject networks through a fuzzy system dynamic model, Frontiers of Engineering Management (2020), 1-16.

[37] F. Blanco-Mesa, E. León-Castro and J.M. Merigó, A bibliometric analysis of aggregation operators, Applied Soft Computing 81(4) (2019), 105488.

[38] M. Olazabal-Lugo, E. Leon-Castro, L.F. Espinoza-Audelo, J.M. Merigo and A.M. Gil Lafuente, Forgotten effects and heavy moving averages in exchange rate forecasting, Economic Computation \& Economic Cybernetics Studies \& Research 53(4) (2019). 